\title{
ANALISIS NILAI TAMBAH DAN KEUNTUNGAN AGROINDUSTRI EMPING MELINJO DI DESA BERNUNG KECAMATAN GEDONG TATAAN KABUPATEN PESAWARAN
}

\author{
(Added Value and Profit Analysis of Melinjo Chips Agroindustry in Bernung Village Gedong Tataan \\ Sub-District of Pesawaran District)
}

Tiya Ayu Lestari, Muhammad Irfan Affandi, Adia Nugraha

Jurusan Agribisnis, Fakultas Pertanian, Universitas Lampung, Jl. Prof. Dr. Soemantri Brodjonegoro No. 1 Bandar Lampung, 35145, e-mail: irfan.affandi@fp.unila.ac.id

\begin{abstract}
This study aims to analyze added value and profits of melinjo chips agroindustry in Bernung Village. This research was conducted in five melinjo chips agroindustries in Bernung Village, Gedong Tataan Subdistrict, Pesawaran Regency. Data collection was conducted in January 2019. The data were analyzed using qualitative sis and quantitative descriptive analyses. The calculation of added value used Hayami added value method. There are two types of added value of melinjo chips such as uncooked melinjo chips and cooked melinjo chips. The results showed that added value is a positive value, meaning that both kinds of chips agroindustries are feasible to be developed. The value added of uncooked melinjo chips is higher than that of cooked chips. The $R / C$ over total cost is 1.20, meaning that the emping melinjo agroindustry in Bernung Village, Gedong Tataan Subdistrict, Pesawaran Regency is a profitable and viable business since $R / C$ value is more than one.
\end{abstract}

Key words: added value, melinjo chips, profit

\section{PENDAHULUAN}

Agroindustri merupakan salah satu bentuk industri hilir yang berbahan baku produk pertanian dan menekankan pada produk olahan dalam suatu perusahaan atau industri. Agroindustri memerlukan bahan baku untuk ditransformasikan dan menghasilkan suatu produk yang lebih bernilai. Supply bahan baku harus tetap berjalan agar agroindustri terus berproduksi (Saragih 2001).

Kabupaten Pesawaran merupakan kabupaten yang memiliki produksi melinjo tertinggi di Provinsi Lampung yaitu sebesar 108,22 ton (Dinas Pertanian Tanaman Pangan dan Hortikultura Provinsi Lampung 2016). Hal tersebut mendukung para masyarakat di Kabupaten Pesawaran untuk menjalankan usaha emping melinjo dan mendapatkan bahan baku melinjo dari dalam provinsi. Salah satu kabupaten yang memiliki banyak industri kecil dan menengah adalah Desa Bernung Kecamatan Gedong Tataan Kabupaten Pesawaran (Dinas Koperasi Perindustrian dan Perdagangan Kabupaten Pesawaran 2015).

Industri emping melinjo di Desa Bernung Kecamatan Gedong Tataan Kabupaten Pesawaran ini kurang lebih sudah berjalan selama 26 tahun. Terdapat beberapa ukuran emping melinjo yang diproduksi oleh para agroindustri, diantaranya adalah emping cuplis (1 biji) dengan harga kisaran Rp50.000 - 60.000, keprek (2-3 biji), remaja (710) dan benggol (>10 biji) dengan harga kisaran Rp30.000 - 45. 000. Emping cuplis dan emping keprek atau emping biji dua merupakan emping yang menjadi permintaan terbanyak di agroindustri tersebut. Pengolahan emping melinjo merupakan pengelolaan biji melinjo menjadi produk emping melinjo mentah atau setengah jadi dan produk jadi atau produk yang sudah siap dikonsumsi dan memiliki nilai tambah.

Pengolahan hasil yang baik yang dilakukan oleh produsen dapat meningkatkan nilai tambah dari hasil pertanian yang diproses. Bagi petani, kegiatan pengolahan hasil telah dilakukan khususnya bagi petani yang mempunyai fasilitas pengolahan hasil seperti lantai jemur, penggilingan dan penyimpanan. Bagi pengusaha yang berskala besar, kegiatan pengolahan hasil dijadikan kegiatan utama. Hal ini disebabkan dengan pengolahan yang baik maka nilai tambah barang pertanian menjadi meningkat. Di sisi yang lain, khususnya petani dengan skala keterbatasan yang dimiliki sering kali kurang memperhatikan pengolahan hasil pertanian (Soekartawi 2000).

Nilai tambah emping melinjo ini dihitung dari biji melinjo menjadi emping melinjo mentah atau belum siap konsumsi dan menjadi emping melinjo 
olahan atau siap konsumsi, untuk dilihat mana nilai tambah yang lebih tinggi. Nilai tambah akan mempengaruhi tingkat keuntungan agroindustri, semakin tinggi tingkat keuntungan, maka agroindustri akan bisa terus melanjutkan produksinya.

Berdasarkan permasalahan yang telah dijelaskan di atas, tujuan dari penelitian ini yaitu menganalisis nilai tambah produk emping melinjo mentah dan olahan dan menganalisis keuntungan yang dihasilkan oleh agroindustri emping melinjo di Desa Bernung Kecamatan Gedong Tataan Kabupaten Pesawaran.

\section{METODE PENELITIAN}

Penelitian dilakukan di agroindustri emping melinjo di Desa Bernung Kecamatan Gedong Tataan. Penentuan lokasi penelitian dilakukan secara sengaja atau purposive dengan pertimbangan daerah tersebut merupakan sentra produksi emping melinjo di Kabupaten Pesawaran.

Pengambilan sampel kelima pelaku agroindustri emping melinjo di Desa Bernung Kecamatan Gedong Tataan Kabupaten Pesawaran ini diambil secara purposive sampling yaitu mengambil lima agroindustri terbesar yang ada di Desa Bernung. Pengumpulan data dalam penelitian dilaksanakan pada bulan Januari 2019. Metode penelitian yang digunakan dalam penelitian ini adalah metode studi kasus pada agroindustri emping melinjo di Desa Bernung Gedong Tataan, Kabupaten Pesawaran.

Penelitian ini dilakukan dengan menggunakan data primer dan data sekunder. Data primer diperoleh melalui wawancara langsung dengan responden terkait. Data sekunder diperoleh dari lembaga/instansi terkait seperti Badan Pusat Stastistik, Dinas Koperasi Perindustrian dan Perdagangan Kabupaten Pesawaran mengenai jumlah pelaku agroindustri, identitas agroindustri, dan pustaka lain yang terkait.

Nilai tambah dihitung untuk mengetahui seberapa besar selisih harga antara emping melinjo mentah dengan emping melinjo siap konsumsi yang dihasilkan agroindustri emping melinjo di Desa Bernung. Selisih harga tersebut yang akan menambah pendapatan pelaku agroindustri emping melinjo. Perhitungan nilai tambah menggunakan metode Hayami.
Kriteria nilai tambah adalah :

1. Jika NT $>0$, berarti pengembangan agroindustri emping melinjo memberikan nilai tambah hasilnya positif.

2. Jika NT $<0$, berarti pengembangan agroindustri emping melinjo tidak memberikan nilai tambah hasilnya negatif.

Menghitung keuntungan agroindustri emping melinjo:

$\Pi=\quad \mathrm{TR}-\mathrm{TC}$

Keterangan :

$\Pi \quad=$ Keuntungan usaha agroindustri emping melinjo (Rp)

$\mathrm{TR}=$ Penerimaan usaha agroindustri emping melinjo (Rp)

$\mathrm{TC}=$ Biaya total usaha agroindustri emping melinjo ( $\mathrm{Rp})$

Penerimaan dapat dihitung dengan menggunakan rumus sebagai berikut:

$\mathrm{TR}=\mathrm{Q} \times \mathrm{P}$

Keterangan :

$\mathrm{TR}=$ Penerimaan total usaha agroindustri emping melinjo (Rp)

$\mathrm{Q}=$ Jumlah produk emping melinjo $(\mathrm{kg})$

$\mathrm{P}=$ Harga produk emping melinjo (Rp)

Tabel 1. Prosedur perhitungan metode Hayami

\begin{tabular}{|c|c|c|}
\hline No. & Variabel & Nilai \\
\hline 1. & Output (Kg/bulan) & $\mathrm{A}$ \\
\hline \multirow[t]{2}{*}{2.} & Bahan baku(Kg/bulan) & B \\
\hline & Tenaga Kerja & \\
\hline 3. & (HOK/bulan) & $\mathrm{C}$ \\
\hline 4. & Faktor Konversi & $\mathrm{D}=\mathrm{A} / \mathrm{B}$ \\
\hline 5. & Koefisien Tenaga Kerja & $\mathrm{E}=\mathrm{C} / \mathrm{B}$ \\
\hline \multirow[t]{2}{*}{6.} & Harga Output & F \\
\hline & Upah Rata-rata & \\
\hline 7. & Tenaga Kerja (Rp/HOK) & G \\
\hline 8. & Harga bahan baku & $\mathrm{H}$ \\
\hline 9. & Sumbangan input lain & I \\
\hline 10. & Nilai Output & $\mathrm{J}=\mathrm{D} \times \mathrm{F}$ \\
\hline \multirow[t]{2}{*}{11.} & a. Nilai Tambah & $\mathrm{K}=\mathrm{J}-\mathrm{I}-\mathrm{H}$ \\
\hline & b. Rasio Nilai Tambah & $\mathrm{L}=(\mathrm{K} / \mathrm{J}) \times 100 \%$ \\
\hline \multirow[t]{2}{*}{12.} & a. Imbalan Tenaga Kerja & $\mathrm{M}=\mathrm{E} \times \mathrm{G}$ \\
\hline & b. Bagian Tenaga Kerja & $\mathrm{N}=(\mathrm{M} / \mathrm{K}) \times 100(\%)$ \\
\hline \multirow[t]{2}{*}{13.} & a. Keuntungan & $\mathrm{O}=\mathrm{K}-\mathrm{M}$ \\
\hline & b. Tingkat Keuntungan & $\mathrm{P}=\mathrm{O} / \mathrm{K} \times 100(\%)$ \\
\hline \multirow[t]{4}{*}{14.} & Margin Keuntungan & $\mathrm{Q}=\mathrm{J}-\mathrm{H}$ \\
\hline & a. Keuntungan & $\mathrm{R}=\mathrm{O} / \mathrm{Q} \times 100 \%$ \\
\hline & b. Tenaga Kerja & $\mathrm{S}=\mathrm{M} / \mathrm{Q} \times 100 \%$ \\
\hline & c. Input Lain & $\mathrm{T}=\mathrm{I} / \mathrm{Q} \times 100 \%$ \\
\hline
\end{tabular}


Setelah dilakukan analisis keuntungan, kemudian dilakukan analisis $\mathrm{R} / \mathrm{C}$ rasio tujuannya untuk mengetahui kelayakan usaha pada agroindustri emping melinjo. Analisis $\mathrm{R} / \mathrm{C}$ rasio merupakan perbandingan antara penerimaan total dengan biaya total. Analisis rasio ini dilakukan dengan membagi nilai rata-rata keuntungan yang telah dihitung menggunakan analisis keuntungan dengan rata-rata biaya yang dikeluarkan per bulan. Analisis R/C rasio dapat dirumuskan sebagai berikut:

$\mathrm{R} / \mathrm{C}=\mathrm{TR} / \mathrm{TC}$

Keterangan:

$\mathrm{R} / \mathrm{C}=$ Nisbah penerimaan dan biaya

$\mathrm{TR}=$ Total revenue atau penerimaan total (Rp)

$\mathrm{TC}=$ Total cost atau biaya total (Rp)

Menurut Soekartawi (2000) kriteria pengambilan keputusan adalah:

a. Jika $\mathrm{R} / \mathrm{C}>1$, maka suatu usaha mengalami keuntungan, karena penerimaan lebih besar dari biaya.

b. Jika $\mathrm{R} / \mathrm{C}<1$, maka suatu usaha mengalami kerugian, karena penerimaan lebih kecil dari biaya.

c. Jika $\mathrm{R} / \mathrm{C}=1$, maka suatu usaha mengalami impas, karena penerimaan sama dengan biaya.

\section{HASIL DAN PEMBAHASAN}

\section{Analisis Nilai Tambah}

Nilai tambah adalah nilai yang ditambahkan oleh suatu perusahaan atau agroindustri ke bahan-bahan dan jasa-jasa yang dibelinya melalui produksi dan usaha-usaha pemasarannya (Hayami et al 1987). Nilai tambah agroindustri emping melinjo di Desa Bernung merupakan jumlah nilai perbulan. Agroindustri emping melinjo ini terdapat dua jenis nilai tambah yaitu nilai tambah saat emping masih mentah dan emping olahan atau sudah siap konsumsi.

Analisis nilai tambah produk emping melinjo pada agroindustri tersebut menunjukkan bahwa nilai tambah dipengaruhi oleh nilai produk, harga bahan baku yang digunakan dan sumbangan bahan lain. Rincian rata-rata nilai tambah pada agroindustri emping melinjo di Desa Bernung dapat dilihat pada Tabel 2.

Tabel 2 menunjukkan bahwa, besarnya jumlah bahan baku yang digunakan dan besarnya keluaran yang dihasilkan pada emping mentah, maka diperoleh nilai faktor konversi sebesar 0,49 yang artinya dari satu kilogram buah melinjo menghasilkan 0,49 kilogram emping melinjo. Dalam pembuatan satu kilogram emping melinjo, rata-rata sumbangan input lain yang digunakan adalah sebesar Rp1.895, nilai ini diperoleh dari pembagian biaya total rata-rata bahan lain dengan jumlah rata-rata output yang dihasilkan sebesar 438 kilogram melinjo (Hayami et al. 1987). Sumbangan input lain yang paling besar pada pengolahan emping melinjo mentah ini adalah dari penggunaan kayu bakar dan biaya transaksi.

Nilai tambah yang diperoleh dari pengolahan satu kilogram buah melinjo menjadi emping melinjo rata-rata sebesar Rp5.577. Rasio nilai tambah untuk pengolahan emping melinjo sebesar 29 persen yang berarti untuk setiap Rp100,00 nilai produk akan diperoleh nilai tambah sebesar Rp29,00.

Rata-rata keuntungan yang diperoleh dari proses pengolahan bahan baku buah melinjo menjadi emping melinjo sebesar Rp2.247 dengan rata-rata tingkat keuntungan sebesar 40 persen dari nilai produk. Nilai keuntungan tersebut merupakan selisih dari nilai tambah dengan imbalan tenaga kerja.

Besarnya jumlah bahan baku yang digunakan dan besarnya keluaran yang dihasilkan pada emping siap konsumsi, maka diperoleh nilai faktor konversi sebesar 0,51 yang artinya dari satu kilogram buah melinjo menghasilkan 0,51 kilogram emping melinjo. Dalam pembuatan satu kilogram emping melinjo, rata-rata sumbangan input lain yang digunakan adalah $\mathrm{Rp} 8.821$ (Hayami et al. 1987). Sumbangan input lain yang paling besar pada pengolahan emping melinjo ini adalah dari penggunaan minyak dan biaya transaksi.

Nilai tambah yang diperoleh dari pengolahan satu kilogram buah melinjo menjadi emping melinjo rata-rata sebesar Rp5.285. Rasio nilai tambah untuk pengolahan emping melinjo sebesar 22 persen yang berarti untuk setiap Rp100,00 nilai produk akan diperoleh nilai tambah sebesar Rp22,00.

Rata-rata keuntungan yang diperoleh dari proses pengolahan bahan baku buah melinjo menjadi emping melinjo sebesar Rp2.734 dengan rata-rata tingkat keuntungan sebesar 52 persen dari nilai produk. Nilai keuntungan tersebut merupakan 
selisih dari nilai tambah dengan imbalan tenaga kerja.

Nilai keuntungan yang diperoleh dari kegiatan pengolahan emping mentah belum cukup tinggi karena rata-rata tingkat keuntungan belum mencapai 50 persen, sedangkan produk emping melinjo olahan sudah masuk kategori cukup tinggi, karena rata-rata tingkat keuntungannya adalah 52 persen. Analisis nilai tambah produk emping melinjo dipengaruhi oleh nilai produk, harga bahan baku yang digunakan dan sumbangan bahan lain. Nilai tambah produk emping melinjo siap konsumsi pada agroindustri emping melinjo di Desa Bernung menunjukkan nilai tambah positif, artinya usaha pengolahan emping melinjo memberikan nilai tambah positif dan dapat dikembangkan.

Usaha pengolahan emping melinjo mentah pada agroindustri emping melinjo di Desa Bernung masuk dalam agroindustri padat karya, karena nilai balas jasa pemilik faktor produksi lebih tinggi pada tenaga kerja dibandingkan dengan keuntungan. Artinya, agroindustri tersebut akan menyerap tenaga kerja yang ada di sekitar lokasi agroindustri, sehingga agroindustri tersebut mempunyai prospek yang baik untuk dijalankan.

Tabel 2. Nilai tambah agroindustri emping melinjo di Desa Bernung

\begin{tabular}{lrr}
\hline \multicolumn{1}{c}{ Ouput, input, dan harga } & Mentah & $\begin{array}{c}\text { Siap } \\
\text { konsumsi }\end{array}$ \\
\hline Output (Kg/bulan) & 438 & 160 \\
Bahan baku(Kg/bulan) & 888 & 316 \\
Tenaga Kerja (HOK/bulan) & 197 & 154 \\
Faktor Konversi & 0,49 & 0,51 \\
Koefisien Tenaga Kerja & 0,22 & 0,49 \\
Harga Output & 39.500 & 48.400 \\
Upah Rata-rata & & \\
Tenaga Kerja (Rp/HOK) & 15.000 & 5.222 \\
Harga bahan baku(Rp/kg) & 12.000 & 10.400 \\
Sumbangan input lain(Rp) & 2.058 & 8.853 \\
Nilai ouput & 19.472 & 24.506 \\
a. Nilai Tambah & 5.577 & 5.285 \\
b. Rasio Nilai Tambah & 28 & 21 \\
c. Imbalan Tenaga Kerja & 3.330 & 2.551 \\
d. Bagian Tenaga Kerja & 60 & 48 \\
e. Keuntungan & 2.247 & 2.734 \\
f. Tingkat Keuntungan & 40 & 52 \\
Balas Jasa Pemilik Faktor- & & \\
faktor Produksi & & \\
Margin Keuntungan & 7.472 & 14.106 \\
a. Keuntungan & 40 & 19 \\
b. Tenaga Kerja & 45 & 18 \\
c. Input Lain & 25 & 63 \\
\hline & &
\end{tabular}

Penelitian ini berbanding terbalik dengan penelitian Sari, Hasyim, Widjaya (2017) yang masuk dalam agroindustri pada modal, karena nilai balas jasa pemilik faktor produksi lebih tinggi pada keuntungan dibandingkan dengan tenaga kerja. Artinya, agroindustri tersebut menggunakan modal yang besar sehingga teknologi yang digunakan modern.

Hasil perhitungan dan penelitian yang telah dilakukan pada agroindustri emping melinjo di Desa Bernung menunjukkan nilai tambah yang positif, artinya usaha pengolahan emping melinjo mampu memberikan keuntungan bagi pelaku agroindustri, pedagang, dan menambah pendapatan bagi petani dan pengumpul melinjo, sehingga dapat dikembangkan.

\section{Analisis Keuntungan}

Keuntungan merupakan sejumlah penghasilan yang diperoleh agroindustri atas usahanya dalam periode tertentu, baik harian, mingguan ataupun bulanan (Sukirno 2006). Keuntungan agroindustri emping melinjo dihitung dengan periode bulanan dengan menggunakan mengurangi jumlah penerimaan dengan biaya total Rata-rata pendapatan agroindustri emping melinjo di Desa Bernung dapat dilihat pada Tabel 3.

Tabel 3 menunjukan bahwa rata-rata penerimaan agroindustri emping melinjo di Desa Bernung adalah Rp24.961.250/bulan. Total biaya yang dikeluarkan oleh agroindustri dalam memproduksi emping mentah dan emping siap konsumsi di Desa Bernung ini adalah sebesar Rp20.770.082 yang diperoleh dari penjumlahan biaya tunai dan biaya yang diperhitungkan.

Total biaya yang dikeluarkan lebih besar pada emping melinjo mentah dibanding dengan emping melinjo siap konsumsi. Hal ini disebabkan karena bahan baku untuk emping melinjo mentah lebih banyak dibanding dengan emping melinjo siap konsumsi, selain itu harga emping mentah lebih rendah dibanding dengan harga emping siap konsumsi yang mencapai Rp50.000. 
Tabel 3. Analisis keuntungan rata-rata produk emping melinjo pada agroindustri emping melinjo di Desa Bernung

\begin{tabular}{|c|c|c|c|c|c|c|c|c|c|}
\hline \multirow{3}{*}{ No. } & \multirow{3}{*}{ Uraian } & \multicolumn{8}{|c|}{ Per bulan } \\
\hline & & \multicolumn{4}{|c|}{ Mentah } & \multicolumn{4}{|c|}{ Olahan } \\
\hline & & Satuan & Jumlah & Harga & Nilai & Jumlah & Harga & Nilai & Total \\
\hline \multirow[t]{2}{*}{1.} & Penerimaan & & & & & & & & \\
\hline & Produksi & $\mathrm{kg}$ & 438 & 39.500 & 17.281 .250 & 160 & 48.000 & 7.680 .000 & 24.961 .250 \\
\hline \multirow[t]{24}{*}{2.} & Biaya produksi & & & & & & & & \\
\hline & I. Biaya Tunai & & & & & & & & \\
\hline & A. BOP Variabel & & & & & & & & \\
\hline & a) Melinjo & $\mathrm{kg}$ & 710 & 12.000 & 8.520 .000 & 316 & 10.000 & 3.160 .000 & 11.680 .000 \\
\hline & b) Minyak & $\mathrm{L}$ & & & & 51 & 12.500 & 642.500 & 642.500 \\
\hline & c) Penyedap rasa & Pcs & & & & 9 & 35.000 & 308.000 & 308.000 \\
\hline & d) Garam & Pcs & & & & 3,20 & 22.000 & 70.400 & 70.400 \\
\hline & e) Kayu Bakar & kubik & 5 & 52.000 & 249.600 & 3 & 52.000 & 135.200 & 384.800 \\
\hline & f) Pasir & $\mathrm{Kg}$ & & & & 102.429 & & & 90.057 \\
\hline & g) Bawang putih & $\mathrm{kg}$ & & & & - & 35 & 13.000 & 460.200 \\
\hline & h) Kemasan & lembar & 40 & 1.200 & 48.000 & 104 & 933 & 97.067 & 113.600 \\
\hline & i) TKLK & HOK & 158 & 15.000 & 2.364 .000 & 159,00 & 5.222 & 830.333 & 3.194 .333 \\
\hline & j) Biaya transaksi & $\mathrm{Rp}$ & & & 3.048 .571 & & & 328.286 & 3.376 .857 \\
\hline & k) Biaya listrik & $\mathrm{Rp}$ & & & 75.952 & & & 35.238 & 111.190 \\
\hline & B. BOP tetap & & & & & & & & \\
\hline & Total biaya tunai & $\mathrm{Rp}$ & & & 14.306.124 & & & 5.620 .024 & 20.431 .938 \\
\hline & II. Biaya yang diperhitungkan & & & & & & & & \\
\hline & A. BOP Variabel & & & & & & & & \\
\hline & a) TKDK & HOK & 0 & 0 & 0 & 0 & 0 & 0 & 0 \\
\hline & B. BOP Tetap & & & & & & & & \\
\hline & a) Penyusutan pabrik & $\mathrm{Rp}$ & & & 17.394 & & & 11.078 & 28.472 \\
\hline & b) Penyusutan alat & $\mathrm{Rp}$ & & & 177.514 & & & 132.157 & 309.672 \\
\hline & Total biaya diperhitungkan & Rp & & & 194.908 & & & 143.235 & 338.144 \\
\hline & Total Biaya & $\mathrm{Rp}$ & & & 14.501 .032 & & & 5.763 .259 & 20.770 .082 \\
\hline \multirow[t]{3}{*}{3.} & Keuntungan & & & & & & & & \\
\hline & $\begin{array}{l}\text { A. Keuntungan Atas Biaya } \\
\text { Tunai }\end{array}$ & $\mathrm{Rp}$ & & & 2.975 .126 & & & 2.059 .976 & 4.529 .312 \\
\hline & $\begin{array}{l}\text { B. Keuntungan Atas Biaya } \\
\text { Total }\end{array}$ & $\mathrm{Rp}$ & & & 2.975 .126 & & & 1.916 .741 & 4.191 .168 \\
\hline \multirow[t]{3}{*}{4.} & R/C Ratio & & & & & & & & \\
\hline & $\begin{array}{l}\text { A. R/C Ratio Atas Biaya } \\
\text { Tunai }\end{array}$ & & & & 1,21 & & & 1,37 & 1,22 \\
\hline & $\begin{array}{l}\text { B. R/C Ratio Atas Biaya } \\
\text { Total }\end{array}$ & & & & 1,19 & & & 1,33 & 1,20 \\
\hline
\end{tabular}

Setelah menganalisis keuntungan, kemudian dilakukan analisis R/C yang bertujuan untuk mengetahui kelayakan agroindustri yang sedang diteliti. Agroindustri emping melinjo mentah dan emping melinjo siap konsumsi memiliki nilai R/C atas biaya tunai dan $\mathrm{R} / \mathrm{C}$ atas biaya total lebih dari satu, artinya usaha agroindustri emping melinjo di Desa Bernung Kecamatan Gedong Tataan Kabupaten Pesawaran mengalami keuntungan dan layak diusahakan karena penerimaan lebih besar dari biaya. Keuntungan yang diperoleh tersebut dapat mendorong agroindustri untuk terus berupaya agar agroindustri dapat memenuhi permintaan konsumen, baik pada saat bahan baku sedang tidak musim panen ataupun saat sedang musim panen, sehingga agroindustri dapat memperoleh keuntungan yang lebih tinggi. Hal tersebut berbanding lurus dengan penelitian Sari, Zakaria, Affandi (2015) bahwa usaha agroindustri layak untuk dikembangkan.
Pesanan dan harga jual yang meningkat seperti pada waktu mendekati hari raya akan meningkatkan permintaan sehingga agroindustri memproduksi dengan jumlah yang cukup banyak dan dapat menaikkan keuntungan agroindustri, sebaliknya jika permintaan dan harga turun, maka keuntungan yang diperoleh oleh agroindustri dapat mengakibatkan penurunan juga. $\mathrm{Hal}$ ini berbanding lurus dengan penelitian Agustina, Ismono, Nugraha (2015) bahwa permintaan yang meningkat akan menaikkan produksi agroindustri dan menyebabkan perubahan keuntungan.

\section{KESIMPULAN}

Agroindustri emping melinjo di Desa Bernung, Kecamatan Gedong Tataan, Kabupaten Pesawaran memperoleh nilai tambah yang positif yaitu sebesar Rp5.577 untuk jenis emping mentah dan Rp5.285 untuk jenis emping siap konsumsi. 
Agroindustri emping melinjo memiliki R/C > 1, sehingga agrondustri tersebut merupakan unit usaha yang menguntungkan dan layak untuk diusahakan.

\section{DAFTAR PUSTAKA}

Agustina DR, Ismono RH, dan Nugraha A. 2015. Harga pokok produksi, nilai tambah, dan prospek pengembangan agroindustri marning di Kecamatan Gedong Tataan Kabupaten Pesawaran. JIIA. 3(2): 157-164. http://jurnal. fp.unila.ac.id/index.php/JIA/article/view/1034. [15 November 2018].

Dinas Koperasi Perindustrian dan Perdagangan Kabupaten Pesawaran. 2015 Daftar Industri Kecil Menengah di Kabupaten Pesawaran Tahun 2015. Pesawaran.

Dinas Pertanian Tanaman Pangan dan Hortikultura. 2016. Luas panen, produksi dan produktivitas tanaman melinjo Provinsi Lampung menurut Kabupaten/Kota Tahun 2015. Bandar Lampung.

Hayami Y. 1987. Agricultural Marketing and Processing in Upland Java. A Perspective From A Sunda Village. CGPRT Centre. Bogor.
Mantra IB. 2004. Demografi Umum. Penerbit Pustaka Pelajar. Yogyakarta.

Nasution. 2003. Metode Penelitian Naturalistik Kualitatif. Tarsito. Bandung.

Saragih B. 2001. Agribisnis Paradigma Baru Pembangunan Ekonomi Berbasis Pertanian, Kumpulan Pemikiran. PT Surveyor Indonesia dan Pusat StudiPembangunan LP-IPB. Jakarta.

Sari IMR, Zakaria WA, dan Affandi MI. 2015. Kinerja produksi, nilai tambah, dan strategi pengembangan agroindustri emping melinjo di Kota Bandar Lampung. JIIA. 3 (1): 18-25. https://media.neliti.com/media/publications/13 321-ID-kinerja-produksi-dan-nilai-tambah-ag ro-industri-emping-melinjo-di-kota-bandar-la m.pdf. [15 November 2018].

Sari RY, Hasyim AI, dan Widjaya S. 2017. Rantai pasok dan nilai tambah keripik nangka pada agroindustri keripik panda alami di Kecamatan Gedong Tataan Kabupaten Pesawaran. JIIA. 6 (3): 257-262. http:// jurnal.fp.unila.ac.id/index.php/JIA/article/vie w/1034. [05 Febriari 2019].

Soekartawi. 2000. Pengantar Agroindustri. PT Raja Grafindo Persada. Jakarta.

Sukirno S. 2006. Mikro Ekonomi Teori Pengantar. Edisi Ketiga. Raja Grafindo Persada. Jakarta. 